\title{
Toxicological Effects of Cadmium on Mammalian Testis
}

\author{
Qiqi Zhu ${ }^{1,2}$, Xiaoheng $\mathrm{Li}^{1}$ and Ren-Shan $\mathrm{Ge}^{1,2 *}$ \\ ${ }^{1}$ Department of Obstetrics and Gynecology, The Second Affiliated Hospital and Yuying Children's Hospital of Wenzhou \\ Medical University, Wenzhou, China, ${ }^{2}$ Department of Anesthesiology, The Second Affiliated Hospital and Yuying Children's \\ Hospital of Wenzhou Medical University, Wenzhou, China
}

Cadmium is a heavy metal, and people are exposed to it through contaminated foods and smoking. In humans and other mammals, cadmium causes damage to male testis. In this review, we summarize the effects of cadmium on the development and function of the testis. Cadmium causes severe structural damage to the seminiferous tubules, Sertoli cells, and blood-testis barrier, thus leading to the loss of sperm. Cadmium hinders Leydig cell development, inhibits Leydig cell function, and induces Leydig cell tumors. Cadmium also disrupts the vascular system of the testis. Cadmium is a reactive oxygen species inducer and possibly induces DNA damage, thus epigenetically regulating somatic cell and germ cell function, leading to male subfertility/infertility.

Keywords: cadmium, reactive oxygen species, male infertility, spermatogenesis, leydig cell, testosterone

\section{OPEN ACCESS}

Edited by:

Md Saidur Rahman,

Chung-Ang University, South Korea

Reviewed by:

Soterios A. Kyrtopoulos,

National Hellenic Research

Foundation, Greece

Richard John Brennan,

Sanofi U. S., United States

*Correspondence:

Ren-Shan Ge

r_ge@yahoo.com

Specialty section:

This article was submitted to

Toxicogenomics,

a section of the journal

Frontiers in Genetics

Received: 11 December 2019

Accepted: 30 April 2020

Published: 26 May 2020

Citation:

Zhu Q, Li X and Ge R-S (2020)

Toxicological Effects of Cadmium on

Mammalian Testis.

Front. Genet. 11:527.

doi: 10.3389/fgene.2020.00527

\section{INTRODUCTION}

Infertility rate continues to trend higher in this century and about $15 \%$ of couples are infertile. Male causes of infertility account for $40-50 \%$ (Kilchevsky and Honig, 2012). Globally, the sperm count and semen quality of men persistently trend lower (Carlsen et al., 1992; Geoffroy-Siraudin et al., 2012). The causes of male infertility are complex and the etiology of about $50 \%$ of male infertility remains unknown. Although genetic factors can explain a few percentages of male infertility, increasing environmental pollution might also contribute to the persistent increase of male infertility (Nordkap et al., 2012; Gao et al., 2015). Males are exposed to environmental pollutants throughout their life cycle, including embryonic period. Although environmental pollutants are directly exposed to the testes of adult mammals and inhibit spermatogenesis, male subfertility/infertility might also originate from fetal exposure to toxicants (Skakkebaek et al., 2001). The fetal exposure to environmental chemicals leads to reproductive tract anomalies such as cryptorchidism and hypospadias, testicular cancer, and subfertility/infertility in males, referred to as Testicular Dysgenesis Syndrome (TDS) (Skakkebaek et al., 2001). A rise of cryptorchidism and testicular cancer might significantly contribute to male subfertility/infertility (Jorgensen et al., 2011; Loebenstein et al., 2019). Although the exact mechanism for TDS is still unclear, the epigenetic regulations are involved since the fetal exposure to toxicants can persistently cause male subfertility/infertility at adulthood (Skinner et al., 2015).

Environmental pollutants include a family of heavy metals. Exposure to heavy metals has been linked to male infertility (Wirth and Mijal, 2010). One of the heavy metals is cadmium ion $\left(\mathrm{Cd}^{2+}\right.$ or Cd). Numerous studies in animal models (mainly rodents) and growing evidence from human epidemiological research point to the adverse effects of $\mathrm{Cd}$ on male fertility. The present review describes Cd action and its mechanisms, including endocrine-disruption, reactive oxygen species (ROS) generation and epigenetic regulation for the etiology of male subfertility/infertility. Since male subfertility/infertility also comes from environmentally exposed fetuses, we briefly introduce the development of testis in rodents and/or humans. 


\section{CADMIUM EXPOSURE AND ITS FATE IN MAMMALS}

$\mathrm{Cd}$ is a common environmental pollutant in many industrial processes and smoking (Faroon et al., 2012). Cd is a byproduct of the production of other metals such as zinc, lead or copper, and is mainly used in batteries, pigments, coatings and electroplating, plastic stabilizers, and other applications (Faroon et al., 2012). Cd enters the food chain after contamination (Chirinos-Peinado and Castro-Bedrinana, 2020). Humans are exposed to Cd through pollutants in air, drinking water, and food (Faroon et al., 2012). Smoking is another source of Cd (Siu et al., 2009a). After smoking, the Cd content of smokers is $4-5$ times higher than that of non-smokers (Takiguchi and Yoshihara, 2006). On average, the daily Cd intake of humans is $1.06 \mu \mathrm{g} / \mathrm{kg}$ body weight (Wan et al., 2013). Despite the lower intake of Cd, the elimination half-life of Cd is longer ( $\sim 20-40$ years in humans) and can accumulate in the body (Wan et al., 2013). Besides, the testis is the tissue in which Cd can accumulate in large amounts (Thompson and Bannigan, 2008). After 14 days of treatment in rats, the $\mathrm{Cd}$ in the testes was 100 times higher than that in the blood (Aoyagi et al., 2002). Numerous studies have shown that mammalian testes are sensitive organs against Cd (Wong et al., 2004; Takiguchi and Yoshihara, 2006; Sadik, 2008). Cd can cause male reproductive toxicity, including testicular injury (Wan et al., 2013).

\section{EFFECTS OF CADMIUM ON SPERMATOGENESIS}

\section{Effects of Cd on Sertoli Cells (SCs)}

Mammalian testis contains two compartments, the seminiferous epithelium (SCs bind together to support spermatogenesis), and the interstitial compartment, in which Leydig cells (LCs) secrete androgen and peptide hormone such as insulin-like 3 (INSL3) to regulate the development of the male reproductive tract, the descent of testis and the spermatogenesis.

SCs play a critical role in the assembly of the testis cords during the fetal and neonatal periods (Rebourcet et al., 2014, 2016; Smith et al., 2015). When the SCs in the testis of newborn mice are eliminated, the tubule structure is lost, and subsequent development of adult Leydig cells (ALCs) in the adult testis is severely blocked (Rebourcet et al., 2014). In adult testes, SCs are essential for maintaining spermatogenesis, and elimination of the SCs in adult testes can lead to loss of germ cells (Rebourcet et al., 2014). Besides, in the fetus, SCs secrete anti-Müllerian hormone $(\mathrm{AMH})$, which causes the regression of Müllerian duct (Unal et al., 2018). In the fetal life of rodents and humans, the number of SCs increases exponentially, and then slows down after birth and reaches adult levels in early puberty (Sharpe et al., 2003; O'shaughnessy et al., 2007; Guo et al., 2020; Tan et al., 2020).

Cd affects SC development during fetal and neonatal periods (Table 1). A single intraperitoneal injection (ip.) of low doses of Cd to rats on GD12 down-regulates the expression of SC genes (Dhh and Fshr), although this does not affect its number (Li et al., 2018). Exposure to Cd (1-2 mg/kg, sc) in pregnant and lactating rats can cause vacuolation of SCs and loss of
TABLE 1 | Action of cadmium on testicular cells.

\begin{tabular}{|c|c|c|c|}
\hline Species & Cell & Action & References \\
\hline \multicolumn{4}{|c|}{ SERTOLI CELL } \\
\hline Pig & Sertoli cell & $\begin{array}{l}\text { DNA damage }(+) \text {, } \\
\text { apoptosis }(+)\end{array}$ & Zhang et al., 2018 \\
\hline Rat & Sertoli cell & $\begin{array}{l}\text { Dhh and Fshr } \\
\text { expression }(-) \\
\text { Ultrastructure alteration } \\
(+), \\
\text { Cytoplasmic } \\
\text { vacuolation (+), } \\
\text { Cytoskeleton } \\
\text { disarrangement (+) } \\
\text { BTB disruption }(+)\end{array}$ & $\begin{array}{l}\text { Hew et al., 1993; Haffor } \\
\text { and Abou-Tarboush, } \\
\text { 2004; Wong et al., } \\
\text { 2005; de Souza Predes } \\
\text { et al., 2011; Xiao et al., } \\
\text { 2014; Li et al., 2018; } \\
\text { Zhu et al., } 2018\end{array}$ \\
\hline Human & Sertoli cell & BTB disruption (+) & Xiao et al., 2014 \\
\hline Mouse & Sertoli cell & $\begin{array}{l}\text { Mitochondrial alteration } \\
(+)\end{array}$ & Bizarro et al., 2003 \\
\hline \multicolumn{4}{|c|}{ LEYDIG CELL } \\
\hline Rat & Fetal Leydig cell & $\begin{array}{l}\text { Steroidogenic gene } \\
\text { expression (-) } \\
\text { Testosterone synthesis } \\
(-) \\
\text { Ins/3 expression (-) }\end{array}$ & $\begin{array}{l}\text { Hu et al., 2014; Li } \\
\text { et al., } 2018\end{array}$ \\
\hline Rat & Adult Leydig cell & $\begin{array}{l}\text { Leydig cell } \\
\text { development }(-) \\
\text { Leydig cell number }(-) \\
\text { Testosterone synthesis } \\
(-) \\
\text { Leydig cell volume }(-) \\
\text { Cytoplasm } \\
\text { vacuolization }(+) \\
\text { Leydig cell tumor }(+) \\
\text { Leydig cell } \\
\text { regeneration }(-)\end{array}$ & $\begin{array}{l}\text { Mckenna et al., 1996; } \\
\text { Waalkes et al., 1997, } \\
\text { 1999; Biswas et al., } \\
\text { 2001; Gunnarsson } \\
\text { et al., 2004; Blanco } \\
\text { et al., 2007, 2010; } \\
\text { Cupertino et al., 2017; } \\
\text { Wu et al., 2017; } \\
\text { Mahmoudi et al., 2018; } \\
\text { Tian et al., } 2018\end{array}$ \\
\hline Mouse & Adult Leydig cell & $\begin{array}{l}\text { Steroidogenic gene } \\
\text { expression (-) } \\
\text { Testosterone secretion } \\
(-) \\
\text { Leydig cell number }(-) \\
\text { Leydig cell cytoplasm } \\
\text { alteration }(+) \\
\text { Leydig cell tumors }(+)\end{array}$ & $\begin{array}{l}\text { Hu et al., 2014; } \\
\text { Mahmoudi et al., } 2018\end{array}$ \\
\hline \multicolumn{4}{|c|}{ GERM CELLS } \\
\hline Rat & Spermatogenesis & $\begin{array}{l}\text { Spermatogonia } \\
\text { number (-), } \\
\text { Massive germ cell } \\
\text { death }(+)\end{array}$ & $\begin{array}{l}\text { Cupertino et al., 2017; } \\
\text { Mahmoudi et al., } 2018\end{array}$ \\
\hline Human & Sperm & Motility (-) & Vine, 1996 \\
\hline Rat & Sperm & $\begin{array}{l}\text { Sperm motility }(-) \text {, } \\
\text { Sperm count }(-) \text {, } \\
\text { In vitro fertilization rate } \\
(-), \\
\text { Early embryonic } \\
\text { development }(-)\end{array}$ & $\begin{array}{l}\text { Zhao et al., 2017; } \\
\text { Mahmoudi et al., } 2018\end{array}$ \\
\hline
\end{tabular}

BTB, blood-testis barrier; (-) or (+), inhibition or stimulation.

germ cells in adult seminiferous epithelium (Bekheet, 2011). Cd inhibits proliferation and induces apoptosis and DNA damage of immature SCs in the piglet testis (Zhang et al., 2018). Cd inhibits the interaction between neonatal SC and gonocyte via p38 MAPK 
signaling in the SC-gonocyte co-culture system in vitro (Yu et al., 2008).

During puberty and adulthood, SCs form a blood-testis barrier (BTB) to support spermatogenesis. Spermatogenesis takes place in the seminiferous tubules, which are formed by SCs. Spermatogenesis invovles the self-renewal and proliferation of spernatogenia, and then differentiation, cell cycle progression from type $\mathrm{B}$ spermatogonia to preleptotene spermatocytes outside of the BTB, cell cycle progression from zygotene and pachytene to diplotene spermatocytes, a transition of round spermatids to elongated spermatids and then spermatozoa via spermiogenesis, and spermiation (Wu et al., 2019). In the adult testis, SCs play key roles in supporting the self-renewal and differentiation of spermatogonia into mature sperm (Su et al., 2018). SCs provide a basic link between the interstitium and the seminiferous tubule (Su et al., 2018). Therefore, SCs play essential roles in spermatogenesis.

Adult SCs are the target of Cd (Table 1). Exposure of rats to $\mathrm{Cd}$ of $1 \mathrm{mg} / \mathrm{kg}$ daily by gavage for 28 days can cause severe ultrastructure changes in adult SCs (Haffor and AbouTarboush, 2004). Rats exposed to a single dose of Cd ( $3 \mu \mathrm{mol} / \mathrm{kg})$ show vacuolation in the SC cytoplasm and irregular chromatin condensation in late spermatids (de Souza Predes et al., 2011). Exposure to $\mathrm{Cd}$ by inhalation for 28 days can cause severe mitochondrial changes in SCs of adult mice (Bizarro et al., 2003). Molecular biology findings indicate that $\mathrm{Cd}$ perturbs the cytoskeleton of SC actin by disrupting F-actin organization in human SCs at $0.5-20 \mu \mathrm{M}$ after altering the expression of actin regulatory proteins Arp3 and Eps8 in vitro (Xiao et al., 2014).

\section{Effect of Cd on BTB Formed by SCs}

The BTB in a mammalian testis consists of a specialized junction between adjacent SCs near the basement membrane in the seminiferous tubule (Wu et al., 2019). The BTB is the target of $\mathrm{Cd}$ (Table 1). Cd induces the disruption of BTB in rodent models. Cd attacks BTB by inducing defragmentation of actin filaments of SCs in rodents (Wong et al., 2005) and humans (Xiao et al., 2014). The mechanistic finding demonstrates that $\mathrm{Cd}$ disturbs BTB in the rat testis in vivo by up-regulating transforming growth factor $\beta 3$ (TGF- $\beta 3$ ), which in turn activates p38 MAPK signaling (Lui et al., 2003; Wong et al., 2004). Interestingly, Cd also activates the JNK pathway at the same time to up-regulate $\alpha 2$-macroglobulin to counteract its adverse effects because JNK specific inhibitor can aggravate Cd-induced damage on BTB (Wong et al., 2005), indicating the JNK signaling is the protective mechanism in SCs after Cd treatment. Cd treatment to SCs at $5-10 \mu \mathrm{M}$ for $8 \mathrm{~h}$ can disrupt SC tight junction assembly by down-regulating the expression of occludin and urokinase plasminogen activator without causing any apparent cytotoxicity and $\mathrm{T}$ can protect it (Chung and Cheng, 2001).

Focal adhesion kinase (FAK) is a non-receptor protein tyrosine kinase to regulate BTB (Wan et al., 2014). FAK regulates tight junction proteins (e.g., occludin and ZO-1) in the rat testis (Siu et al., 2009b,c). Cd can down-regulate FAK expression (Siu et al., 2009c). The knockdown of FAK in SCs with a functional tight junction can protect SCs from Cd-induced disruption (Siu et al., 2009b). This indicates that Cd targets FAK to regulate BTB.

\section{Effect of Cd on Sperm Development}

$\mathrm{Cd}$ affects sperm development (Table 1). Rats exposed to a single dose of $(0.67-1.1 \mathrm{mg} / \mathrm{kg})$ of $\mathrm{Cd}$ for 7 days show disorganization of the seminiferous epithelium (Cupertino et al., 2017). After 28 days of oral administration of $\mathrm{Cd}(5 \mathrm{mg} / \mathrm{kg})$ for 28 days, rat's sperm count, motility, and viability decline (Nna et al., 2017). When rats are exposed to $\mathrm{Cd}(0.2 \mathrm{mg} / \mathrm{kg}$, sc) for 15 days, the seminiferous tubules of their testes are disarranged, the number of germ cells decreases (Jahan et al., 2014). Adult male rats have significantly damaged seminiferous tubules after 56 days of exposure to $\mathrm{Cd}(1.15 \mathrm{mg} / \mathrm{kg}$, i.p) (Leite et al., 2013). Cd ( $3 \mathrm{mg} / \mathrm{kg}$, sc, once a week) exposure to rats for 4 weeks also contract seminiferous tubules and deplete germ cells and increase multinucleated giant cells (Rajendar et al., 2012).

\section{Effects of Cd on Mature Sperm Function}

$\mathrm{Cd}$ affects mature sperm function (Table 1). After in vitro treatment with human and mouse sperm, $\mathrm{Cd}$ remarkably reduces sperm motility and progressive motility (Zhao et al., 2017). Shortterm treatment of Cd (30 min) will not influence sperm motility, but significantly reduces the in vitro fertilization rate to egg and delays early embryonic development in mice, suggesting that $\mathrm{Cd}$ works epigenetically (Zhao et al., 2017). Cd also lowers human sperm motility and forward motility (Zhao et al., 2017).

\section{HUMAN EPIDEMIOLOGICAL STUDIES OF CADMIUM}

The effects of $\mathrm{Cd}$ on human fertility have been reviewed in several papers (de Angelis et al., 2017; Kumar and Sharma, 2019). Evidence from epidemiological studies supports the positive correlation between $\mathrm{Cd}$ and male subfertility/infertility. Fifty cases of hypospadias and healthy control boys are analyzed for the association with serum heavy metal concentrations oncentrations (Sharma et al., 2014). Serum concentrations of $\mathrm{Cd}$ in hypospadias boys are significantly higher (Sharma et al., 2014). Comparing the serum and semen Cd levels of 60 infertile adult males in Nigeria (40 oligospermia and 20 azoospermia) with 40 normal spermia controls, the data have shown that $\mathrm{Cd}$ and FSH levels of these infertile patients are significant higher (Akinloye et al., 2006). Infertile couples (501 cases) in Rockville of the United States show higher Cd levels in their blood, indicating that $\mathrm{Cd}$ has reproductive toxicity at environmentally relevant levels (Buck Louis et al., 2012). Men with varicocele usually show increased accumulation of $\mathrm{Cd}$ in the testicular blood system, and the percentage of sperm cell apoptosis in their testes also generally increases (Benoff et al., 2004). Meta-analysis with high-quality studies can provide superior evidence. Zhang et al. collect 11 research articles (including 1093 infertile subjects and 614 controls) and perform a meta-analysis and find that a high level of $\mathrm{Cd}$ in semen causes male infertility (Zhang et al., 2019). De Franciscis et al. investigated fifty healthy men and found that blood Cd concentrations were positively associated with a reduction of sperm motility and teratozoospermia (de Franciscis et al., 2015). He et al. measured the urinary levels of oxidative stress markers, semen quality, and urinary levels of 
three heavy metals including arsenic, Cd and lead in 1020 men and indicate that that higher levels of urinary arsenic, $\mathrm{Cd}$ and lead are negatively associated with semen quality and positively associated with increased oxidative stress markers (He et al., 2020).

Cd also causes endocrine-disrupting effects on males. Xu et al. reported in a study of 2,286 men (aged 18 years and older) that there is a negative association between blood Cd levels with total T and sex hormone-binding globulin (SHBG) (Chen et al., 2016). Kresovich et al. examined the associations in males in National Health and Nutritional Examination Survey (NHANES) data from 1999 to 2004 for blood Cd and SHBG and found that blood Cd was positively associated with SHBG (Kresovich et al., 2015). These studies indicate that Cd might be negatively associated with total or free $\mathrm{T}$ levels.

\section{MECHANISMS OF CADMIUM-MEDIATED ACTION}

\section{The Endocrine-Disrupting Effects}

LCs are endocrine cells in the testis. There are two populations of LCs in rodents, fetal LC (FLC) and adult LC (ALC). On GD12 in mice or GD14 in rats, a set of fetal Leydig cell (FLC) progenitors are differentiated into FLCs after the regulation by SC-secreted factors, such as desert hedgehog (Yao et al., 2002) and platelet-derived growth factor (Brennan et al., 2003) and aristaless-related homeobox (Miyabayashi et al., 2013). In rodents, FLCs double cell number and persist in the testis until birth (Barsoum and Yao, 2009). FLCs undergo apoptosis and gradually disappear although some persist in the adult testis (Kerr and Knell, 1988; Shima et al., 2015). FLCs play an essential role in the development of the male reproductive tract by synthesizing androgen (mainly, T) and insulin-like 3 (INSL3). Androgen promotes the development of both the internal and external genitalia of the male fetus and descent of testis (Ye et al., 2017). In male mammals, androgen promotes the Wolffian duct to develop into the epididymis, vas deferens, and seminal vesicles (Ye et al., 2017). INSL3 promotes the initial descent of the testis by regulating gubernaculum shortening (Adham et al., 2000). The shortening of the gubernaculum draws the testes from the kidney position across the abdomen to the entrance of the inguinal canal (Emmen et al., 2000).

ALCs emerge as progenitor Leydig cells in the late second week after birth in mice and rats, and express some LC steroidogenic enzymes, such as cytochrome P450 side-chain cleavage enzyme (Cyp11a1), 3 $\beta$-hydroxysteroid dehydrogenase ( $H s d 3 b, H s d 3 b 6$ in the mouse and $H s d 3 b 1$ for the rat ALC) isoforms, and cytochrome P450 17 $\alpha$-hydroxylase/17,20-lyase (Cyp17a1) but lack the last-step $\mathrm{T}$ synthetic enzyme, 17 $\beta$ hydroxysteroid dehydrogenase 3 (Hsd17b3) (Ge and Hardy, 1998; Wang et al., 2003). Progenitor Leydig cells transit into the immature stage, in which immature Leydig cells (ILCs) express $H s d 17 b 3$, but they have a high expression of $5 \alpha$-reductase 1 (Srd5a1) during 4-5th weeks (Ge and Hardy, 1998; Wang et al., 2003). Then, they finally mature into ALCs, which synthesize T with full capacity, after the silence of Srd5a1 (Ge and Hardy,
1998; Wang et al., 2003). Besides, ALCs also express luteinizing hormone $(\mathrm{LH})$ receptor (Lhcgr) to receive signaling from pituitary-secreted LH, and high-density lipoprotein receptor (Scarb1) and steroidogenic acute regulatory protein (Star) for cholesterol transport.

As mentioned above, FLCs secrete two important hormones, $\mathrm{T}$ and INSL3, to stimulate the development of the male reproductive tract and the descent of the testis. Perinatal exposure to environmental toxicants can cause TDS (Wang et al., 2019). Cd affects the development and function of FLCs (Table 1). Pregnant rats receiving a single dose of $\mathrm{Cd}$ $(0.25,0.5$, and $1.0 \mathrm{mg} / \mathrm{kg}$, i.p.) can remarkably decrease $\mathrm{T}$ synthesis of the fetal testis, lower FLC number, down-regulate the expression of FLC genes (Lhcgr, Scarb1, Star, Cyp11a1, Hsd3b1, and Cyp17a1) of male offspring (Li et al., 2018) and it also shortens the anogenital distance, an androgen-dependent process, of male offspring ( $\mathrm{Li}$ et al., 2018). In the testis of rats that are perinatally (during gestation and lactation) exposed to $\mathrm{Cd}$ and the development of ALCs is delayed, with an increase in the number of ILCs (Srd5a1-expressing cells), and decrease in cAMP/PKA signaling and down-regulation of T steroidogenic enzymes (Tian et al., 2018).

Cd also affects the development and function of ALCs (Table 1). Adult male mice exposed to Cd $(0.015 \mathrm{~g} / \mathrm{L}$ in drinking water) at $1,3,6$, and 12 months have significantly decreased ALC cell volume (Blanco et al., 2007). Male mice exposed to Cdcontaining food (about 1-2 g per animal) for half a year have lower T secretion and lower expression of Star, Cyp11a1, and Cyp17a1 (Hu et al., 2014). Mature male mice fed with 0.015 $\mathrm{g} / \mathrm{L} \mathrm{Cd}$ in drinking water for $0.25,0.5,1$, and 1.5 years exhibit cytoplasmic vacuolization in ALCs, reduction of ALC number and formation of LC tumors (Blanco et al., 2010). After 7 days of exposure to a single dose $(0.67-1.1 \mathrm{mg} / \mathrm{kg})$ of $\mathrm{Cd}$, serum $\mathrm{T}$ levels in rats are significantly reduced (Cupertino et al., 2017). Adult male rats exposed to Cd (sc) have increased PGF2 $\alpha$ and decreased serum T levels and down-regulated Star (Gunnarsson et al., 2004). Adult male rats exposed to Cd (0.5 or $1.0 \mathrm{mg} / \mathrm{kg}$, i.p. single dose) also have significantly delayed LC regeneration, lower T levels and down-regulated expression of Lhcgr, Scarb1, Star, Cyp11a1, Hsd3b1, Cyp17a1, and Hsd17b3 (Wu et al., 2017). Adult rats receiving a single dose of $\mathrm{Cd}(0.45 \mathrm{mg} / \mathrm{kg}, \mathrm{sc})$ have a significantly low HSD3B1 and HSD17B3 activity and serum $\mathrm{T}$ levels and accessory sex organ weight (Biswas et al., 2001). Further in vitro studies have shown that $\mathrm{Cd}$ also lowers $\mathrm{T}$ synthesis and DNA integrity of LCs (Liu et al., 2013).

Cd concentration-dependently lowers cAMP and downregulates the expression of dihydrolipoamide dehydrogenase in R2C tumor LCs (Zhang et al., 2011). Primary LCs that are exposed to 10,20 , and $40 \mu \mathrm{M}$ of $\mathrm{Cd}$ for $24 \mathrm{~h}$ also show the increase in DNA damage and lower T secretion (Yang et al., 2003). Besides, Cd also induces LC tumors (Waalkes et al., 1999) and disrupts vascular cells (Leite et al., 2015).

\section{Cadmium Induces ROS Production}

There is increasing evidence that the mechanism by which $\mathrm{Cd}$ mediates impaired male fertility is related to the production of ROS in the testes. ROS is composed of hydroxyl, peroxyl, 
and hydroperoxyl radicals, superoxide, nitric oxide, and nitrogen dioxide. The homeostasis of ROS is maintained by the production of ROS and the antioxidant system. This disruption of homeostasis leads to oxidative stress, which hinders the development and function of sperm and somatic cells or induces apoptosis (Morielli and O'flaherty, 2015). Cd induces ROS generation in the testis. Cd $(6.5 \mathrm{mg} / \mathrm{kg})$ exposure to adult rats for 5 days increases oxidative stress, including increased peroxidation and nitric oxide and decreased GSH level, catalase, superoxide dismutase (SOD), glutathione peroxidase, and glutathione reductase, thus up-regulating the expression of pro-apoptotic protein BCL-2-associated-X-protein (Bax) and tumor necrosis factor- $\alpha$ and down-regulating the expression of the anti-apoptotic gene $(B c l 2)$ in the testis, leading to a decrease of cell proliferation (Elmallah et al., 2017). Rats that are exposed to $\mathrm{Cd}(1.5 \mathrm{mg} / \mathrm{kg})$ for 13,25 , and 39 days have the increase in ROS production and possess the reduction of the diameter of the seminiferous tube, the decrease of the number of spermatogonia, SCs, and LCs, and the decrease in sperm motility and count, as well as the inhibition of T synthesis (Mahmoudi et al., 2018). Cd exposure to adult mice ( $1 \mathrm{mg} / \mathrm{kg}$, i.p.) for 5 and 8 weeks increases lipid peroxidation and decreases SOD, catalase, and peroxidase in the testis, leading to an increase in sperm abnormality and decrease in sperm count (Acharya et al., 2008).

Exposure of $\mathrm{Cd}(40 \mathrm{mg} / \mathrm{L})$ to rats for 30 days significantly lowers testis and seminal vesicle weights and decreases serum $\mathrm{T}$ levels and sperm count as well as sperm motility by increasing ROS levels and suppressing catalase and SOD activity (Amara et al., 2008). Cd exposure to adult male rats after a single dose ( $2 \mathrm{mg} / \mathrm{kg}, \mathrm{sc}$ ) for $24 \mathrm{~h}$ induces ROS generation and decreases SOD and catalase activity in the testis, thus disrupting the BTB and vitamin $\mathrm{C}$ can antagonize $\mathrm{Cd}$-induced $\mathrm{BTB}$ damage by inhibiting TGF- $\beta 3$ activation and p38 MAPK phosphorylation (Chen et al., 2018). Cd exposure to rats increases ROS level and decreases glutathione peroxidase and superoxide dismutase activity, thus leading to the down-regulation of Star and Hsd3b1 and $H s d 17 b 3$ and lowering secretion of T (Sen Gupta et al., 2004). Cd exposure to rats after i.p. $0.025 \mathrm{mg} / \mathrm{kg} /$ day for 15 days induces ROS production and lowers SOD, catalase, glucose-6phosphate dehydrogenase, and glutathione-S-transferase activity in the mitochondrion (Pandya et al., 2012). This exposure causes a remarkable reduction of the expression of LC steroidogenic enzymes ( $H s d 3 b 1$ and $H s d 17 b 3$ ) and T synthesis (Pandya et al., 2012). Rats exposed to $0.2 \mathrm{mg} / \mathrm{kg} \mathrm{Cd} \mathrm{(sc)} \mathrm{for} 5$ days have significantly high lipid peroxidation and low catalase, peroxidase, SOD, and glutathione reductase activity in the testis (Jahan et al., 2014). Rats exposed to Cd (3 mg/kg, sc, once a week) for 4 weeks display shrunken tubules and depletion of germ cells, increase of multinucleated giant cells, and degeneration of LCs after inducing significantly high ROS levels and low SOD and catalase activity and low amount of GSH (Sugiura et al., 2005; Rajendar et al., 2012). Cd (30 $\mu \mathrm{mol} / \mathrm{kg})$ exposure to rats remarkably increases lipid peroxidation and formation of $\mathrm{H}_{2} \mathrm{O}_{2}$ in LCs and decreases glutathione reductase and catalase activities after $12 \mathrm{~h}$ treatment and induces LC tumors later (Koizumi and $\mathrm{Li}, 1992)$. Cd, after being administered in a single dose (1 mg $\mathrm{Cd} / \mathrm{kg}$, i.p.) into male mice, causes interstitial hemorrhages, LC death, and numerous atypical mitoses of the spermatocytes after 3 and 6 months (Selypes et al., 1992).

The in vitro system also shows that $\mathrm{Cd}$ induces $\mathrm{ROS}$ production in various testicular cells. In vitro SC-germ cell co-culture shows that $\mathrm{Cd}$ induces ROS and decreases GSH, thus causing cytochrome $\mathrm{c}$ release, caspase- 3 activation and SC apoptosis (Khanna et al., 2011). Cd exposure to rat R2C tumor LC cells at $10-160 \mu \mathrm{M}$ for $24 \mathrm{~h}$ also causes mitochondrial damage and lowers Star expression level and then inhibits steroid secretion, possibly by increasing ROS levels and decreasing SOD2 activity (Yan et al., 2019). Cd down-regulates the expression of Star, Cyp11a1, and Hsd3b1 by inhibiting cAMP/PKA/ERK1/2 and PKC signaling after inhibiting of dihydrolipoamide dehydrogenase activity in $\mathrm{R} 2 \mathrm{C}$ tumor LCs (Ji et al., 2015). Primary rat ILCs exposed to Cd have a reduced mitochondrial membrane potential and increased ROS MAPK-extracellular-regulated kinase activity, increased cell death, and a decreased transcription of Hsd3b1 (Khanna et al., 2016). Cd concentration-dependently inhibits hCG- and dbcAMP-stimulated $\mathrm{T}$ production in vitro (Laskey and Phelps, 1991). After $48 \mathrm{~h}$ of Cd treatment with $0.03 \mathrm{mmol} / \mathrm{kg} \mathrm{Cd}$, it can induce DNA damage and apoptosis in rat testes (Xu et al., 1996).

Cd exposure to mouse TM3 tumor LCs also reduces LC viability and increases cell apoptosis after increasing ROS production and JNK phosphorylation and c-Jun expression, then activates apoptosis-related proteins, cleaved-caspase 3 and cleaved-PARP, and decreases BCL2. These effects can be reversed by antioxidant $\mathrm{N}$-acetyl-L-cysteine and JNK inhibitor (Lu et al., 2019). Exposure of Cd to TM3 tumor LCs decreases SOD2 and GSH contents by targeting the Nrf2/ARE signaling pathway, thereby decreasing $\mathrm{T}$ production (Yang et al., 2019).

All antioxidants, including vitamin C (Acharya et al., 2008; Pandya et al., 2012; Chen et al., 2018), vitamin E (Acharya et al., 2008; Jahan et al., 2014), Fragaria ananassa extract (Elmallah et al., 2017), Ficus religiosa (Jahan et al., 2014), cyanidin-3-Oglucoside (Yan et al., 2019), N-acetyl-L-cysteine (Khanna et al., 2016; Lu et al., 2019), sulphoraphane (Jahan et al., 2014), green tea (Mahmoudi et al., 2018), quercetin (Nna et al., 2017), Paullinia cupana (Leite et al., 2013), alpha-tocopherol (Rajendar et al., 2012), selenium (Bekheet, 2011), and zinc (Villanueva et al.,

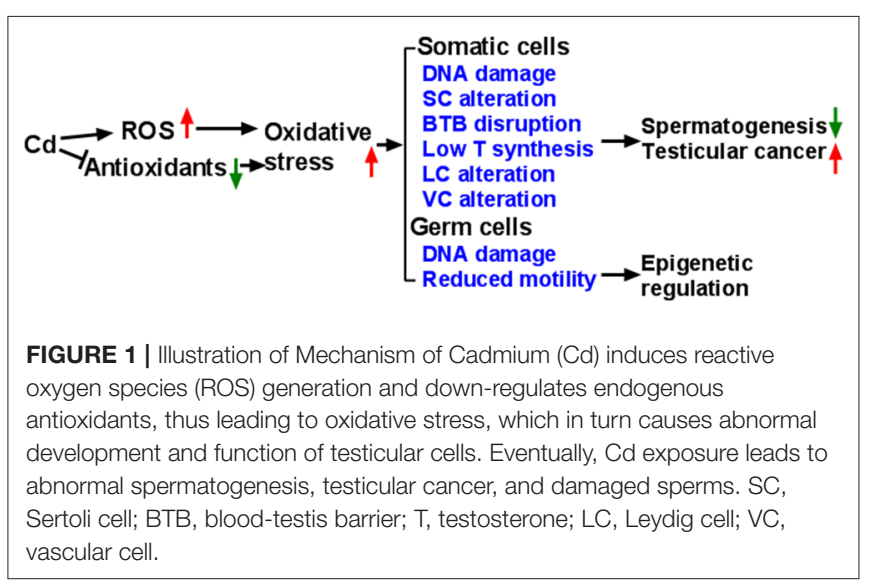


2005; Burukoglu and Baycu, 2008) can partially and completely antagonize the Cd-mediated effect, suggesting that the major pathway of Cd is ROS induction.

\section{Epigenetic Regulation of Cd}

Although interesting epigenetic effects are observed in the germline after Cd treatment (Zhao et al., 2017), environmentally induced epigenetic changes related to infertility are described in somatic cells (such as SCs and LCs), which support spermatogenesis. Rats exposed to $\mathrm{Cd}$ (1, 2, or $4 \mathrm{mg} / \mathrm{kg} /$ day) on days 3-7 after birth causes abnormal DNA methylation on day 70 after birth and increases sperm apoptosis, and exhibits a degradation of seminiferous tubules (Zhu et al., 2011). Exposure of rats to Cd-contaminated soil for 1 year leads to $\mathrm{Cd}$ accumulation and increases the genome-wide methylation status and the expression of DNA methyltransferase (Dnmt 3a/3b) in the testis, suggesting epigenetic changes (Nakayama et al., 2019). Treatment of mouse TM3 LC cell line with Cd can downregulate the expression of DNA methyltransferase (Singh et al., 2009), also indicating an epigenetic regulation and a possible cancer formation.

In other cell types, $\mathrm{Cd}$ can also up-regulate the expression of two oncogenic epigenetic regulators, viz. protein arginine methyltransferase 5 and the polycomb repressive complex 2 member enhancer of Zeste homolog 2, which in turns lead to an increased global level of symmetric dimethylarginine, H4R3me2s and H3K27me3, and it can also induce global DNA hypomethylation due to a decrease in DNA methyltransferase

\section{REFERENCES}

Acharya, U. R., Mishra, M., Patro, J., and Panda, M. K. (2008). Effect of vitamins $\mathrm{C}$ and $\mathrm{E}$ on spermatogenesis in mice exposed to cadmium. Reprod. Toxicol. 25, 84-88. doi: 10.1016/j.reprotox.2007.10.004

Adham, I. M., Emmen, J. M., and Engel, W. (2000). The role of the testicular factor INSL3 in establishing the gonadal position. Mol. Cell. Endocrinol. 160, 11-16. doi: 10.1016/S0303-7207(99)00188-4

Akinloye, O., Arowojolu, A. O., Shittu, O. B., and Anetor, J. I. (2006). Cadmium toxicity: a possible cause of male infertility in Nigeria. Reprod. Biol. 6, 17-30.

Amara, S., Abdelmelek, H., Garrel, C., Guiraud, P., Douki, T., Ravanat, J. L., et al. (2008). Preventive effect of zinc against cadmium-induced oxidative stress in the rat testis. J. Reprod. Dev. 54, 129-134. doi: 10.1262/jrd.18110

Aoyagi, T., Ishikawa, H., Miyaji, K., Hayakawa, K., and Hata, M. (2002). Cadmiuminduced testicular damage in a rat model of subchronic intoxication. Reprod. Med. Biol. 1, 59-63. doi: 10.1046/j.1445-5781.2002.00010.x

Barsoum, I. B., and Yao, H. H. (2009). Fetal Leydig cells: progenitor cell maintenance and differentiation. J. Androl. 31, 11-15. doi: 10.2164/jandrol.109.008318

Bekheet, S. H. (2011). Comparative effects of repeated administration of cadmium chloride during pregnancy and lactation and selenium protection against cadmium toxicity on some organs in immature rats' offsprings. Biol. Trace Elem. Res. 144, 1008-1023. doi: 10.1007/s12011-011-9084-Z

Benoff, S. H., Millan, C., Hurley, I. R., Napolitano, B., and Marmar, J. L. (2004). Bilateral increased apoptosis and bilateral accumulation of cadmium in infertile men with left varicocele. Hum. Reprod. 19, 616-627. doi: 10.1093/humrep/deh139

Biswas, N. M., Sen Gupta, R., Chattopadhyay, A., Choudhury, G. R., and Sarkar, M. (2001). Effect of atenolol on cadmium-induced testicular toxicity in male rats. Reprod. Toxicol. 15, 699-704. doi: 10.1016/S0890-6238(01)00184-8 expression. This may be involved in the epigenetic regulation of Cd-mediated cancer formation (Ghosh et al., 2019).

\section{CONCLUSION}

It is now generally accepted that the mammalian testes are very sensitive to $\mathrm{Cd}$, leading to changes in the testicular biochemical function. Cd induces the production of ROS and reduces the activity of antioxidative enzymes, thereby causing oxidative damage to the testes (Figure 1). Cd also epigenetically regulates testicular cells. Cd induces vacuolation and destruction of seminiferous epithelium, abnormal changes in SC ultrastructure. After damaging SC function, Cd disrupts BTB, increases the seminiferous tubule permeability and disrupts spermatogenesis. Cd disrupts the development and function of LCs by inducing DNA damage and apoptosis, and down-regulating the expression of the steroidogenesis-related genes, resulting in decreased $\mathrm{T}$ secretion. Much work is required to explore the events that occur during Cd-induced testicular injury.

\section{AUTHOR CONTRIBUTIONS}

QZ and XL wrote this review. R-SG edited the manuscript.

\section{FUNDING}

This work was partially supported by Department of Health of Zhejiang Province (11-CX29) and NSFC (81730042).

Bizarro, P., Acevedo, S., Nino-Cabrera, G., Mussali-Galante, P., Pasos, F., AvilaCosta, M. R., et al. (2003). Ultrastructural modifications in the mitochondrion of mouse Sertoli cells after inhalation of lead, cadmium or lead-cadmium mixture. Reprod. Toxicol. 17, 561-566. doi: 10.1016/S0890-6238(03)00096-0

Blanco, A., Moyano, R., Molina Lopez, A. M., Blanco, C., Flores-Acuna, R., GarciaFlores, J. R., et al. (2010). Preneoplastic and neoplastic changes in the Leydig cells population in mice exposed to low doses of cadmium. Toxicol. Ind. Health 26, 451-457. doi: 10.1177/0748233710371111

Blanco, A., Moyano, R., Vivo, J., Flores-Acuna, R., Molina, A., Blanco, C., et al. (2007). Quantitative changes in the testicular structure in mice exposed to low doses of cadmium. Environ. Toxicol. Pharmacol. 23, 96-101. doi: 10.1016/j.etap.2006.07.008

Brennan, J., Tilmann, C., and Capel, B. (2003). Pdgfr-alpha mediates testis cord organization and fetal Leydig cell development in the XY gonad. Genes Dev. 17, 800-810. doi: 10.1101/gad.1052503

Buck Louis, G. M., Sundaram, R., Schisterman, E. F., Sweeney, A. M., Lynch, C. D., Gore-Langton, R. E., et al. (2012). Heavy metals and couple fecundity, the LIFE Study. Chemosphere 87, 1201-1207. doi: 10.1016/j.chemosphere.2012.01.017

Burukoglu, D., and Baycu, C. (2008). Protective effects of zinc on testes of cadmium-treated rats. Bull. Environ. Contam. Toxicol. 81, 521-524. doi: 10.1007/s00128-007-9211-x

Carlsen, E., Giwercman, A., Keiding, N., and Skakkebaek, N. E. (1992). Evidence for decreasing quality of semen during past 50 years. BMJ 305, 609-613. doi: 10.1136/bmj.305.6854.609

Chen, C., Wang, N., Nie, X., Han, B., Li, Q., Chen, Y., et al. (2016). Blood cadmium level associates with lower testosterone and sex hormone-binding globulin in Chinese men: from SPECT-China study, 2014. Biol. Trace Elem. Res. 171, 71-78. doi: 10.1007/s12011-015-0526-x

Chen, N., Su, P., Wang, M., and Li, Y. M. (2018). Ascorbic acid inhibits cadmium-induced disruption of the blood-testis barrier by regulating oxidative 
stress-mediated p38 MAPK pathways. Environ. Sci. Pollut. Res. Int. 25, 21713-21720. doi: 10.1007/s11356-018-2138-4

Chirinos-Peinado, D. M., and Castro-Bedrinana, J. I. (2020). Lead and cadmium blood levels and transfer to milk in cattle reared in a mining area. Heliyon 6:e03579. doi: 10.1016/j.heliyon.2020.e03579

Chung, N. P., and Cheng, C. Y. (2001). Is cadmium chloride-induced inter-sertoli tight junction permeability barrier disruption a suitable in vitro model to study the events of junction disassembly during spermatogenesis in the rat testis? Endocrinology 142, 1878-1888. doi: 10.1210/endo.142.5.8145

Cupertino, M. C., Novaes, R. D., Santos, E. C., Neves, A. C., Silva, E., Oliveira, J. A., et al. (2017). Differential susceptibility of germ and leydig cells to cadmium-mediated toxicity: impact on testis structure, adiponectin levels, and steroidogenesis. Oxid. Med. Cell. Longev. 2017:3405089. doi: $10.1155 / 2017 / 3405089$

de Angelis, C., Galdiero, M., Pivonello, C., Salzano, C., Gianfrilli, D., Piscitelli, P., et al. (2017). The environment and male reproduction: the effect of cadmium exposure on reproductive function and its implication in fertility. Reprod. Toxicol. 73, 105-127. doi: 10.1016/j.reprotox.2017.07.021

de Franciscis, P., Ianniello, R., Labriola, D., Ambrosio, D., Vagnetti, P., Mainini, G., et al. (2015). Environmental pollution due to cadmium: measure of semen quality as a marker of exposure and correlation with reproductive potential. Clin. Exp. Obstet. Gynecol. 42, 767-770.

de Souza Predes, F., Monteiro, J. C., Matta, S. L., Garcia, M. C., and Dolder, H. (2011). Testicular histomorphometry and ultrastructure of rats treated with cadmium and Ginkgo biloba. Biol. Trace Elem. Res. 140, 330-341. doi: $10.1007 /$ s12011-010-8702-5

Elmallah, M. I. Y., Elkhadragy, M. F., Al-Olayan, E. M., and Abdel Moneim, A. E. (2017). Protective effect of fragaria ananassa crude extract on cadmiuminduced lipid peroxidation, antioxidant enzymes suppression, and apoptosis in rat testes. Int. J. Mol. Sci. 18:957. doi: 10.3390/ijms18050957

Emmen, J. M. A., Mcluskey, A., Adham, I. M., Engel, W., Grootegoed, J. A., and Brinkmann, A. O. (2000). Hormonal control of gubernaculum development during testis descent: gubernaculum outgrowth in vitro requires both insulin-like factor and androgen. Endocrinology 141, 4720-4727. doi: 10.1210/endo.141.12.7830

Faroon, O., Ashizawa, A., Wright, S., Tucker, P., Jenkins, K., Ingerman, L., et al. (2012). Toxicological Profile for Cadmium. Atlanta (GA): Agency for Toxic Substances and Disease Registry.

Gao, Y., Mruk, D. D., and Cheng, C. Y. (2015). Sertoli cells are the target of environmental toxicants in the testis - a mechanistic and therapeutic insight. Expert Opin. Ther. Targets 19, 1073-1090. doi: 10.1517/14728222.2015.10 39513

Ge, R. S., and Hardy, M. P. (1998). Variation in the end products of androgen biosynthesis and metabolism during postnatal differentiation of rat Leydig cells. Endocrinology 139, 3787-3795. doi: 10.1210/endo.139.9.6183

Geoffroy-Siraudin, C., Loundou, A. D., Romain, F., Achard, V., Courbiere, B., Perrard, M. H., et al. (2012). Decline of semen quality among 10932 males consulting for couple infertility over a 20-year period in Marseille, France. Asian J. Androl. 14, 584-590. doi: 10.1038/aja.2011.173

Ghosh, K., Chatterjee, B., Behera, P., and Kanade, S. R. (2019). The carcinogen cadmium elevates CpG-demethylation and enrichment of NFYA and E2F1 in the promoter of oncogenic PRMT5 and EZH2 methyltransferases resulting in their elevated expression in vitro. Chemosphere 242:125186. doi: 10.1016/j.chemosphere.2019.125186

Gunnarsson, D., Svensson, M., Selstam, G., and Nordberg, G. (2004). Pronounced induction of testicular $\operatorname{PGF}(2$ alpha) and suppression of testosterone by cadmium-prevention by zinc. Toxicology 200, 49-58. doi: 10.1016/j.tox.2004.03.003

Guo, J., Nie, X., Giebler, M., Mlcochova, H., Wang, Y., Grow, E. J., et al. (2020). The dynamic transcriptional cell Atlas of testis development during human puberty. Cell Stem Cell 26, 262-276.e4. doi: 10.1016/j.stem.2019.12.005

Haffor, A. S., and Abou-Tarboush, F. M. (2004). Testicular cellular toxicity of cadmium : transmission electron microscopy examination. J. Environ. Biol. 25, 251-258.

He, Y., Zou, L., Luo, W., Yi, Z., Yang, P., Yu, S., et al. (2020). Heavy metal exposure, oxidative stress and semen quality: exploring associations and mediation effects in reproductive-aged men. Chemosphere 244:125498. doi: $10.1016 /$ j.chemosphere.2019.125498
Hew, K. W., Ericson, W. A., and Welsh, M. J. (1993). A single low cadmium dose causes failure of spermiation in the rat. Toxicol. Appl. Pharmacol. 121, 15-21. doi: 10.1006/taap.1993.1123

Hu, H., Lu, X., Cen, X., Chen, X., Li, F., and Zhong, S. (2014). RNA-Seq identifies key reproductive gene expression alterations in response to cadmium exposure. Biomed Res. Int. 2014:529271. doi: 10.1155/2014/529271

Jahan, S., Zahra, A., Irum, U., Iftikhar, N., and Ullah, H. (2014). Protective effects of different antioxidants against cadmium induced oxidative damage in rat testis and prostate tissues. Syst. Biol. Reprod. Med. 60, 199-205. doi: 10.3109/19396368.2014.912363

Ji, X., Li, Z., Chen, H., Li, J., Tian, H., Li, Z., et al. (2015). Cytotoxic mechanism related to dihydrolipoamide dehydrogenase in Leydig cells exposed to heavy metals. Toxicology 334, 22-32. doi: 10.1016/j.tox.2015.05.003

Jorgensen, N., Vierula, M., Jacobsen, R., Pukkala, E., Perheentupa, A., Virtanen, H. E., et al. (2011). Recent adverse trends in semen quality and testis cancer incidence among Finnish men. Int. J. Androl. 34:e37-48. doi: $10.1111 /$ j.1365-2605.2010.01133.x

Kerr, J. B., and Knell, C. M. (1988). The fate of fetal Leydig cells during the development of the fetal and postnatal rat testis. Development 103, 535-544.

Khanna, S., Lakhera, P. C., and Khandelwal, S. (2011). Interplay of early biochemical manifestations by cadmium insult in sertoli-germ coculture: an in vitro study. Toxicology 287, 46-53. doi: 10.1016/j.tox.2011.05.013

Khanna, S., Mitra, S., Lakhera, P. C., and Khandelwal, S. (2016). Nacetylcysteine effectively mitigates cadmium-induced oxidative damage and cell death in Leydig cells in vitro. Drug Chem. Toxicol. 39, 74-80. doi: 10.3109/01480545.2015.1028068

Kilchevsky, A., and Honig, S. (2012). Male factor infertility in 2011: semen quality, sperm selection and hematospermia. Nat. Rev. Urol. 9, 68-70. doi: 10.1038/nrurol.2011.234

Koizumi, T., and Li, Z. G. (1992). Role of oxidative stress in single-dose, cadmium-induced testicular cancer. J. Toxicol. Environ. Health 37, 25-36. doi: 10.1080/15287399209531654

Kresovich, J. K., Argos, M., and Turyk, M. E. (2015). Associations of lead and cadmium with sex hormones in adult males. Environ. Res. 142, 25-33. doi: 10.1016/j.envres.2015.05.026

Kumar, S., and Sharma, A. (2019). Cadmium toxicity: effects on human reproduction and fertility. Rev. Environ. Health 34, 327-338. doi: 10.1515/reveh-2019-0016

Laskey, J. W., and Phelps, P. V. (1991). Effect of cadmium and other metal cations on in vitro Leydig cell testosterone production. Toxicol. Appl. Pharmacol. 108, 296-306. doi: 10.1016/0041-008X(91)90119-Y

Leite, R., Peloso, E. F., Gadelha, F. R., and Dolder, M. A. (2015). Environmentally realistic doses of cadmium as a possible etiologic agent for idiopathic pathologies. Biol. Trace Elem. Res. 168, 133-140. doi: 10.1007/s12011-015-0322-7

Leite, R. P., Predes, F. S., Monteiro, J. C., Freitas, K. M., Wada, R. S., and Dolder, H. (2013). Advantage of Guarana (Paullinia cupana Mart.) supplementation on cadmium-induced damages in testis of adult Wistar rats. Toxicol. Pathol. 41, 73-79. doi: 10.1177/0192623312447541

Li, X., Liu, J., Wu, S., Zheng, W., Li, H., Bao, S., et al. (2018). In utero single low-dose exposure of cadmium induces rat fetal Leydig cell dysfunction. Chemosphere 194, 57-66. doi: 10.1016/j.chemosphere.2017.11.159

Liu, Q., Gu, J. H., Yuan, Y., Liu, X. Z., Wang, Y. J., Wang, H. D., et al. (2013). Effect of cadmium on rat Leydig cell testosterone production and DNA integrity in vitro. Biomed. Environ. Sci. 26, 769-773. doi: 10.3967/0895-3988.2013.09.009

Loebenstein, M., Thorup, J., Cortes, D., Clasen-Linde, E., Hutson, J. M., and Li, R. (2019). Cryptorchidism, gonocyte development, and the risks of germ cell malignancy and infertility: a systematic review. J. Pediatr. Surg. S00223468(19)30450-6. doi: 10.1016/j.jpedsurg.2019.06.023

Lu, H., Zhang, H., Gao, J., Li, Z., Bao, S., Chen, X., et al. (2019). Effects of perfluorooctanoic acid on stem Leydig cell functions in the rat. Environ. Pollut. 250, 206-215. doi: 10.1016/j.envpol.2019.03.120

Lui, W. Y., Wong, C. H., Mruk, D. D., and Cheng, C. Y. (2003). TGF-beta3 regulates the blood-testis barrier dynamics via the p38 mitogen activated protein (MAP) kinase pathway: an in vivo study. Endocrinology 144, 1139-1142. doi: 10.1210/en.2002-0211

Mahmoudi, R., Azizi, A., Abedini, S., Hemayatkhah Jahromi, V., Abidi, H., and Jafari Barmak, M. (2018). Green tea improves rat sperm quality and reduced 
cadmium chloride damage effect in spermatogenesis cycle. J. Med. Life 11, 371-380. doi: 10.25122/jml-2018-0005

Mckenna, I. M., Bare, R. M., and Waalkes, M. P. (1996). Metallothionein gene expression in testicular interstitial cells and liver of rats treated with cadmium. Toxicology 107, 121-130. doi: 10.1016/0300-483X(95)03252-B

Miyabayashi, K., Katoh-Fukui, Y., Ogawa, H., Baba, T., Shima, Y., Sugiyama, N., et al. (2013). Aristaless related homeobox gene, Arx, is implicated in mouse fetal Leydig cell differentiation possibly through expressing in the progenitor cells. PLoS ONE 8:e68050. doi: 10.1371/journal.pone.0068050

Morielli, T., and O'flaherty, C. (2015). Oxidative stress impairs function and increases redox protein modifications in human spermatozoa. Reproduction 149, 113-123. doi: 10.1530/REP-14-0240

Nakayama, S. M. M., Nakata, H., Ikenaka, Y., Yabe, J., Oroszlany, B., Yohannes, Y. B., et al. (2019). One year exposure to $\mathrm{Cd}$ - and $\mathrm{Pb}$-contaminated soil causes metal accumulation and alteration of global DNA methylation in rats. Environ. Pollut. 252, 1267-1276. doi: 10.1016/j.envpol.2019.05.038

Nna, V. U., Ujah, G. A., Mohamed, M., Etim, K. B., Igba, B. O., Augustine, E. R., et al. (2017). Cadmium chloride-induced testicular toxicity in male wistar rats; prophylactic effect of quercetin, and assessment of testicular recovery following cadmium chloride withdrawal. Biomed. Pharmacother. 94, 109-123. doi: 10.1016/j.biopha.2017.07.087

Nordkap, L., Joensen, U. N., Blomberg Jensen, M., and Jorgensen, N. (2012). Regional differences and temporal trends in male reproductive health disorders: semen quality may be a sensitive marker of environmental exposures. Mol. Cell. Endocrinol. 355, 221-230. doi: 10.1016/j.mce.2011.05.048

O'shaughnessy, P. J., Baker, P. J., Monteiro, A., Cassie, S., Bhattacharya, S., and Fowler, P. A. (2007). Developmental changes in human fetal testicular cell numbers and messenger ribonucleic acid levels during the second trimester. J. Clin. Endocrinol. Metab. 92, 4792-4801. doi: 10.1210/jc.2007-1690

Pandya, C., Pillai, P., Nampoothiri, L. P., Bhatt, N., Gupta, S., and Gupta, S. (2012). Effect of lead and cadmium co-exposure on testicular steroid metabolism and antioxidant system of adult male rats. Andrologia 44(Suppl. 1), 813-822. doi: 10.1111/j.1439-0272.2010.01137.x

Rajendar, B., Bharavi, K., Rao, G. S., Kishore, P. V., Kumar, P. R., Kumar, C. S., et al. (2012). Protective effect of alpha-tocopheral on biochemical and histological alterations induced by cadmium in rat testes. Indian J. Physiol. Pharmacol. $55,213-220$.

Rebourcet, D., O'shaughnessy, P. J., Monteiro, A., Milne, L., Cruickshanks, L., Jeffrey, N., et al. (2014). Sertoli cells maintain Leydig cell number and peritubular myoid cell activity in the adult mouse testis. PLoS ONE 9:e105687. doi: 10.1371/journal.pone.0105687

Rebourcet, D., Wu, J., Cruickshanks, L., Smith, S. E., Milne, L., Fernando, A., et al. (2016). Sertoli cells modulate testicular vascular network development, structure, and function to influence circulating testosterone concentrations in adult male mice. Endocrinology 157, 2479-2488. doi: 10.1210/en.2016-1156

Sadik, N. A. (2008). Effects of diallyl sulfide and zinc on testicular steroidogenesis in cadmium-treated male rats. J. Biochem. Mol. Toxicol. 22, 345-353. doi: 10.1002/jbt.20247

Selypes, A., Serenyi, P., Boldog, I., Bokros, F., and Takacs, S. (1992). Acute and "long-term" genotoxic effects of $\mathrm{CdCl} 2$ on testes of mice. J. Toxicol. Environ. Health 36, 401-409. doi: 10.1080/15287399209531647

Sen Gupta, R., Sen Gupta, E., Dhakal, B. K., Thakur, A. R., and Ahnn, J. (2004). Vitamin $\mathrm{C}$ and vitamin $\mathrm{E}$ protect the rat testes from cadmium-induced reactive oxygen species. Mol. Cells 17, 132-139.

Sharma, T., Banerjee, B. D., Yadav, C. S., Gupta, P., and Sharma, S. (2014). Heavy metal levels in adolescent and maternal blood: association with risk of hypospadias. ISRN Pediatr. 2014:714234. doi: 10.1155/2014/714234

Sharpe, R. M., Mckinnell, C., Kivlin, C., and Fisher, J. S. (2003). Proliferation and functional maturation of Sertoli cells, and their relevance to disorders of testis function in adulthood. Reproduction 125, 769-784. doi: 10.1530/rep.0.1250769

Shima, Y., Matsuzaki, S., Miyabayashi, K., Otake, H., Baba, T., Kato, S., et al. (2015). Fetal Leydig cells persist as an androgen-independent subpopulation in the postnatal testis. Mol. Endocrinol. 29, 1581-1593. doi: 10.1210/me.2015-1200

Singh, K. P., Kumari, R., Pevey, C., Jackson, D., and Dumond, J. W. (2009). Long duration exposure to cadmium leads to increased cell survival, decreased DNA repair capacity, and genomic instability in mouse testicular Leydig cells. Cancer Lett. 279, 84-92. doi: 10.1016/j.canlet.2009.01.023
Siu, E. R., Mruk, D. D., Porto, C. S., and Cheng, C. Y. (2009a). Cadmiuminduced testicular injury. Toxicol. Appl. Pharmacol. 238, 240-249. doi: 10.1016/j.taap.2009.01.028

Siu, E. R., Wong, E. W., Mruk, D. D., Porto, C. S., and Cheng, C. Y. (2009b). Focal adhesion kinase is a blood-testis barrier regulator. Proc. Natl. Acad. Sci. U. S. A. 106, 9298-9303. doi: 10.1073/pnas.0813113106

Siu, E. R., Wong, E. W., Mruk, D. D., Sze, K. L., Porto, C. S., and Cheng, C. Y. (2009c). An occludin-focal adhesion kinase protein complex at the bloodtestis barrier: a study using the cadmium model. Endocrinology 150, 3336-3344. doi: 10.1210/en.2008-1741

Skakkebaek, N. E., Rajpert-De Meyts, E., and Main, K. M. (2001). Testicular dysgenesis syndrome: an increasingly common developmental disorder with environmental aspects. Hum. Reprod. 16, 972-978. doi: 10.1093/humrep/16.5.972

Skinner, M. K., Bhandari, R. K., Haque, M. M., and Nilsson, E. E. (2015). Environmentally induced epigenetic transgenerational inheritance of altered SRY genomic binding during gonadal sex determination. Environ. Epigenet. 1:dvv004. doi: 10.1093/eep/dvv004

Smith, L. B., O'shaughnessy, P. J., and Rebourcet, D. (2015). Cell-specific ablation in the testis: what have we learned? Andrology 3, 1035-1049. doi: 10.1111/andr.12107

Su, D. M., Feng, Y., Wang, L., Wu, Y. L., Ge, R. S., and Ma, X. (2018). Influence of fetal Leydig cells on the development of adult Leydig cell population in rats. J. Reprod. Dev. 64, 223-231. doi: 10.1262/jrd.2017-102

Sugiura, Y., Kashiba, M., Maruyama, K., Hoshikawa, K., Sasaki, R., Saito, K., et al. (2005). Cadmium exposure alters metabolomics of sulfurcontaining amino acids in rat testes. Antioxid. Redox Signal. 7, 781-787. doi: 10.1089/ars.2005.7.781

Takiguchi, M., and Yoshihara, S. (2006). New aspects of cadmium as endocrine disruptor. Environ. Sci. 13, 107-116.

Tan, K., Song, H. W., and Wilkinson, M. F. (2020). Single-cell RNAseq analysis of testicular germ and somatic cell development during the perinatal period. Development 147:dev183251. doi: 10.1242/dev.183251

Thompson, J., and Bannigan, J. (2008). Cadmium: toxic effects on the reproductive system and the embryo. Reprod. Toxicol. 25, 304-315. doi: 10.1016/j.reprotox.2008.02.001

Tian, H., Chen, S., Leng, Y., Li, T., Li, Z., Chen, H., et al. (2018). Exposure to cadmium during gestation and lactation affects development and function of Leydig cells in male offspring. Environ. Toxicol. 33, 351-360. doi: $10.1002 /$ tox. 22522

Unal, E., Yildirim, R., Tekin, S., Demir, V., Onay, H., and Haspolat, Y. K. (2018). A novel mutation of AMHR2 in two siblings with persistent Mullerian duct syndrome. J. Clin. Res. Pediatr. Endocrinol. 10, 387-390. doi: 10.4274/jcrpe.0013

Villanueva, O., Vigueras, R. M., Hernandez, R., Chavira, R., Cardenas, M., Villa, A., et al. (2005). Zinc-induced survival of Leydig cells in Fischer rats (Rattus norvegicus) treated with cadmium chloride. Comp. Med. 55, 533-538.

Vine, M. F. (1996). Smoking and male reproduction: a review. Int. J. Androl. 19, 323-337. doi: 10.1111/j.1365-2605.1996.tb00523.x

Waalkes, M. P., Anver, M., and Diwan, B. A. (1999). Carcinogenic effects of cadmium in the noble $(\mathrm{NBL} / \mathrm{Cr})$ rat: induction of pituitary, testicular, and injection site tumors and intraepithelial proliferative lesions of the dorsolateral prostate. Toxicol. Sci. 52, 154-161. doi: 10.1093/toxsci/52.2.154

Waalkes, M. P., Rehm, S., and Devor, D. E. (1997). The effects of continuous testosterone exposure on spontaneous and cadmium-induced tumors in the male Fischer (F344/NCr) rat: loss of testicular response. Toxicol. Appl. Pharmacol. 142, 40-46. doi: 10.1006/taap.1996.8005

Wan, H. T., Mruk, D. D., Tang, E. I., Xiao, X., Cheng, Y. H., Wong, E. W., et al. (2014). Role of non-receptor protein tyrosine kinases in spermatid transport during spermatogenesis. Semin. Cell Dev. Biol. 30, 65-74. doi: 10.1016/j.semcdb.2014.04.013

Wan, H. T., Mruk, D. D., Wong, C. K., and Cheng, C. Y. (2013). The apical ESBTB-BM functional axis is an emerging target for toxicant-induced infertility. Trends Mol. Med. 19, 396-405. doi: 10.1016/j.molmed.2013.03.006

Wang, G. M., O’shaughnessy, P. J., Chubb, C., Robaire, B., and Hardy, M. P. (2003). Effects of insulin-like growth factor I on steroidogenic enzyme expression levels in mouse leydig cells. Endocrinology 144, 5058-5064. doi: 10.1210/en.2003-0563 
Wang, Y., Ni, C., Li, X., Lin, Z., Zhu, Q., Li, L., et al. (2019). Phthalate-induced fetal Leydig cell dysfunction mediates male reproductive tract anomalies. Front. Pharmacol. 10:1309. doi: 10.3389/fphar.2019.01309

Wirth, J. J., and Mijal, R. S. (2010). Adverse effects of low level heavy metal exposure on male reproductive function. Syst. Biol. Reprod. Med. 56, 147-167. doi: 10.3109/19396360903582216

Wong, C. H., Mruk, D. D., Lui, W. Y., and Cheng, C. Y. (2004). Regulation of blood-testis barrier dynamics: an in vivo study. J. Cell Sci. 117, 783-798. doi: $10.1242 /$ jcs.00900

Wong, C. H., Mruk, D. D., Siu, M. K., and Cheng, C. Y. (2005). Bloodtestis barrier dynamics are regulated by \{alpha\}2-macroglobulin via the c-Jun N-terminal protein kinase pathway. Endocrinology 146, 1893-1908. doi: 10.1210/en.2004-1464

Wu, S., Yan, M., Ge, R., and Cheng, C. Y. (2019). Crosstalk between sertoli and germ cells in male fertility. Trends Mol. Med. 26, 215-231. doi: 10.1016/j.molmed.2019.09.006

Wu, X., Guo, X., Wang, H., Zhou, S., Li, L., Chen, X., et al. (2017). A brief exposure to cadmium impairs Leydig cell regeneration in the adult rat testis. Sci. Rep. 7:6337. doi: 10.1038/s41598-017-06870-0

Xiao, X., Mruk, D. D., Tang, E. I., Wong, C. K., Lee, W. M., John, C. M., et al. (2014). Environmental toxicants perturb human Sertoli cell adhesive function via changes in F-actin organization mediated by actin regulatory proteins. Hum. Reprod. 29, 1279-1291. doi: 10.1093/humrep/deu011

Xu, C., Johnson, J. E., Singh, P. K., Jones, M. M., Yan, H., and Carter, C. E. (1996). In vivo studies of cadmium-induced apoptosis in testicular tissue of the rat and its modulation by a chelating agent. Toxicology 107, 1-8. doi: 10.1016/0300-483X(95)03195-L

Yan, M., Li, L., Mao, B., Li, H., Li, S. Y. T., Mruk, D., et al. (2019). mTORC1/rpS6 signaling complex modifies BTB transport function: an in vivo study using the adjudin model. Am. J. Physiol. Endocrinol. Metab. 317, E121-E138. doi: 10.1152/ajpendo.00553.2018

Yang, J. M., Arnush, M., Chen, Q. Y., Wu, X. D., Pang, B., and Jiang, X. Z. (2003). Cadmium-induced damage to primary cultures of rat Leydig cells. Reprod. Toxicol. 17, 553-560. doi: 10.1016/S0890-6238(03)00100-X

Yang, S. H., Li, P., Yu, L. H., Li, L., Long, M., Liu, M. D., et al. (2019). Sulforaphane protect against Cadmium-induced oxidative damage in mouse Leydigs cells by activating Nrf2/ARE signaling pathway. Int. J. Mol. Sci. 20:630. doi: 10.3390/ijms20030630

Yao, H. H., Whoriskey, W., and Capel, B. (2002). Desert Hedgehog/Patched 1 signaling specifies fetal Leydig cell fate in testis organogenesis. Genes Dev. 16, 1433-1440. doi: $10.1101 /$ gad. 981202
Ye, L., Li, X., Li, L., Chen, H., and Ge, R. S. (2017). Insights into the development of the adult Leydig cell lineage from stem Leydig cells. Front. Physiol. 8:430. doi: 10.3389/fphys.2017.00430

Yu, X., Hong, S., and Faustman, E. M. (2008). Cadmium-induced activation of stress signaling pathways, disruption of ubiquitindependent protein degradation and apoptosis in primary rat Sertoli cell-gonocyte cocultures. Toxicol. Sci. 104, 385-396. doi: 10.1093/toxsci/k fn087

Zhang, J., Huang, B., Hu, G., Zhan, X., Xie, T., Li, S., et al. (2018). Aldosterone blocks rat stem Leydig cell development in vitro. Front. Endocrinol. 9:4. doi: 10.3389/fendo.2018.00004

Zhang, Q., Zou, P., Zhan, H., Zhang, M., Zhang, L., Ge, R. S., et al. (2011). Dihydrolipoamide dehydrogenase and cAMP are associated with cadmium-mediated Leydig cell damage. Toxicol. Lett. 205, 183-189. doi: 10.1016/j.toxlet.2011.06.003

Zhang, Y., Li, S., and Li, S. (2019). Relationship between cadmium content in semen and male infertility: a meta-analysis. Environ. Sci. Pollut. Res. Int. 26, 1947-1953. doi: 10.1007/s11356-018-3748-6

Zhao, L. L., Ru, Y. F., Liu, M., Tang, J. N., Zheng, J. F., Wu, B., et al. (2017). Reproductive effects of cadmium on sperm function and early embryonic development in vitro. PLoS ONE 12:e0186727. doi: 10.1371/journal.pone.0186727

Zhu, H., Li, K., Liang, J., Zhang, J., and Wu, Q. (2011). Changes in the levels of DNA methylation in testis and liver of SD rats neonatally exposed to 5-aza2'-deoxycytidine and cadmium. J. Appl. Toxicol. 31, 484-495. doi: 10.1002/ja t. 1673

Zhu, Q., Ge, F., Dong, Y., Sun, W., Wang, Z., Shan, Y., et al. (2018). Comparison of flavonoids and isoflavonoids to inhibit rat and human $11 \beta$-hydroxysteroid dehydrogenase 1 and 2. Steroids 132, 25-32. doi: 10.1016/j.steroids.2018. 01.013

Conflict of Interest: The authors declare that the research was conducted in the absence of any commercial or financial relationships that could be construed as a potential conflict of interest.

Copyright (C) $2020 \mathrm{Zhu}, \mathrm{Li}$ and Ge. This is an open-access article distributed under the terms of the Creative Commons Attribution License (CC BY). The use, distribution or reproduction in other forums is permitted, provided the original author(s) and the copyright owner(s) are credited and that the original publication in this journal is cited, in accordance with accepted academic practice. No use, distribution or reproduction is permitted which does not comply with these terms. 